\title{
Tubular MCM-41-supported transition metal oxide catalysts for ethylbenzene dehydrogenation reaction
}

\author{
She-Tin Wong, Hong-Ping Lin, Chung-Yuan Mou* \\ Department of Chemistry, National Taiwan University, Taipei 106, Taiwan
}

Received 22 June 1999; received in revised form 5 October 1999; accepted 6 November 1999

\begin{abstract}
MCM-41 in both tubular and particulate morphologies were used as the support for molybdenum and iron oxide catalysts in ethylbenzene dehydrogenation reaction. Different methods of catalyst preparation, such as solution impregnation and physical mixing, were investigated. Nitrogen adsorption-desorption and TEM studies suggest extensive structural defects in tubular MCM-41. The former indicates the presence of an additional pore system at $37 \AA$, while the latter revealed holes of even larger sizes. We thus suggest that the defects make the channels of tubular MCM-41 effectively interconnected and provide a better transport of reactant and product in catalytic reactions. In both fresh and regenerated catalysts, physically mixed samples have lower rates of deactivation and higher catalytic activities than solution impregnated ones. The support of the latter catalysts suffers more structural collapse than the former. The performance of the catalyst seems to depend also on the nature of the support. MCM-41-supported samples performed better than amorphous silica-supported ones, and tubular MCM-41-supported samples are better than particulate MCM-41-supported ones. We interpret the difference in catalytic performance in terms of the increased porosity of the tubular MCM-41 support. (C) 2000 Elsevier Science B.V. All rights reserved.
\end{abstract}

Keywords: MCM-41 tubules; Transition metal oxide catalyst; Physical mixing; Solution impregnation; Ethylbenzene dehydrogenation; Styrene

\section{Introduction}

The synthesis of mesoporous siliceous and aluminosilicate M41S materials [1,2] with large-diameter channel apertures $(25-100 \AA)$ has greatly expanded the capabilities of heterogeneous catalysts [3-8]. It has also opened up a wide range of opportunities in fundamental research and application in various fields of technology [9-18]. However, the catalytic application of MCM-41 will be much more attractive if the desirable catalytic properties of zeolites can be

\footnotetext{
* Corresponding author. Fax: +886-2-2366-0954.

E-mail address: cymou@ms.cc.ntu.edu.tw (C.-Y. Mou)
}

preserved. These properties include high surface area and pore volume, high thermal and hydrothermal stability, and the presence of different types of shape selectivity such as product, reactant and transition state selectivity. Therefore, considerable attention has been focused on tailoring these materials for specific applications and this requires both structural and compositional controls. With the large quantity of accumulated knowledge on supporting metals on carriers such as alumina, silica, carbon and zeolites, and achieving high metal dispersions, the very high surfaces of ordered mesoporous materials offer new possibilities for obtaining highly dispersed metal or metal oxide catalysts. 
There are two disadvantages in applying MCM-41 as a catalyst support. One is its hydrothermal instability; MCM-41 is known to collapse in wet conditions at elevated temperature. This would make its long-term use in a reaction stream doubtful if water is one of the by-products. However, there is some recent progress in improving the hydrothermal stability of MCM-41 [19-21]. The other concern in using MCM-41 in catalytic reaction is its one-dimensionality of the channels. This would make the transport of reactant and product difficult; many catalytic reactions are thus strongly dependent on intra-channel diffusion. Recently, we have disclosed the synthesis of a new family of M41S with tubular morphology via a special delayed-neutralization process [22,23]. The wall of the micron-sized tubules consisted of coaxial cylindrical pores, nanometers in size, that are characteristic of MCM-41. We have found many defects in its structure, which will probably improve the inter-channel diffusion or porosity of the catalyst. We shall demonstrate its advantage as a support in catalytic reaction.

To evaluate the possibility of this novel material as potential catalyst support for transition metal catalysts used in the petroleum industry, we use ethylbenzene dehydrogenation as the probe reaction. The historical evolution of ethylbenzene dehydrogenation process has been summarized by Kearby [24] and others [25]. Ethylbenzene is relatively easy to dehydrogenate, and the reaction can proceed simply via a thermal gas-phase process, as observed by Berthelot in 1869 [26]. However, a much higher selectivity to styrene is obtained by catalytic dehydrogenation reaction in the vapor phase at $580-620^{\circ} \mathrm{C}$, just below the region where thermal cracking becomes important [27]. The catalytic dehydrogenation process has long been an industrial important process for the manufacture of styrene. Alkali-promoted iron oxide is uniquely better than any other catalysts known for ethylbenzene dehydrogenation in the presence of superheated steam $[28,29]$. The reaction was carried out in vapor phase at high temperatures $\left(550-600^{\circ} \mathrm{C}\right)$ with moderate conversions of usually $50 \%$.

The choice of ethylbenzene dehydrogenation as the probe reaction was based on four criteria: (a) a gas phase reaction is preferred in order to avoid the influence of solvent, especially water, on the catalyst system; (b) a facile reaction so that the reaction can be carried out at moderate temperature; (c) a relatively small reactant molecule so that diffusion restriction on the reactant in the pore system is minimized; and (d) a facile equilibrium reaction so that its conversion depends rather strongly on the removal of the product by diffusion. The last two criteria are particularly important when correlating catalytic performance with porosity of support. We choose to study an unpromoted catalyst since it gives relatively low conversion, and hence any morphological effect on the conversion can be clearly observed.

\section{Experimental}

\subsection{Synthesis}

The method used for the synthesis of MCM-41 was adapted from that in our previous reports [22,23]. The gel was prepared at $32^{\circ} \mathrm{C}$ and the general molar ratio of the resultant gel composition is 0.47 surfactant: 59.8 $\mathrm{H}_{2} \mathrm{O}: 0.03 \mathrm{NaAlO}_{2}$ : $1 \mathrm{SiO}_{2}$ : $0.78 \mathrm{NaOH}: 0.32 \mathrm{H}_{2} \mathrm{SO}_{4}$. The surfactant used is hexadecyltrimethylammonium bromide. Acid was added last in the sequence. The rate of acidification of the reaction gel is important in determining the morphology of the product [23], i.e. immediate addition for particulate morphology and gradual addition for tubular morphology. The former was synthesized with pure silica framework, the latter with aluminosilicate framework. The final hydrothermal stage was performed at $100^{\circ} \mathrm{C}$ for 2 days. Further details in morphology control have been previously examined by us [30] and the optimized synthetic conditions of tubular MCM-41 have been reported [31]. Using well-controlled synthetic conditions, one can produce tubular MCM-41 at more than $95 \%$ yield and with very uniform size. The organic template of the as-synthesized MCM-41 was removed by calcination in air at $560^{\circ} \mathrm{C}$ for $6 \mathrm{~h}$.

MCM-41 and amorphous silica-supported catalysts were prepared by several commonly used techniques such as solution impregnation, isomorphous substitution and physical mixing (see Table 1 below). For the impregnation process, the template-free MCM-41 was immersed in a minimum amount of salt solution at the required concentration and was then air-dried overnight. After further drying at $100^{\circ} \mathrm{C}$, the sample was calcined at $500^{\circ} \mathrm{C}$ for $6 \mathrm{~h}$. For the physical mixing 
Table 1

Nomenclature and specification of catalysts

\begin{tabular}{llll}
\hline Catalyst & Method $^{\text {a }}$ & Form & Precursor \\
\hline $\mathrm{Mo} / \mathrm{M}_{\mathrm{P}}$ & $\mathrm{IM}$ & Particulate & $\left(\mathrm{NH}_{4}\right)_{6} \mathrm{Mo}_{7} \mathrm{O}_{24} \cdot 4 \mathrm{H}_{2} \mathrm{O}$ \\
$\mathrm{NaMo} / \mathrm{M}_{\mathrm{P}}$ & $\mathrm{IM}$ & Particulate & $\mathrm{Na}_{2} \mathrm{MoO}_{4} \cdot 2 \mathrm{H}_{2} \mathrm{O}$ \\
$\mathrm{Mo} / \mathrm{SiO}_{2}$ & $\mathrm{IM}$ & Particulate & $\left(\mathrm{NH}_{4}\right)_{6} \mathrm{Mo}_{7} \mathrm{O}_{24} \cdot 4 \mathrm{H}_{2} \mathrm{O}$ \\
$\mathrm{Fe} / \mathrm{M}_{\mathrm{P}}$ & $\mathrm{IM}$ & Particulate & $\left(\mathrm{NH}_{4}\right)_{3} \mathrm{Fe}\left(\mathrm{C}_{2} \mathrm{O}_{4}\right)_{3} \cdot 3 \mathrm{H}_{2} \mathrm{O}$ \\
$\mathrm{Fe} / \mathrm{M}_{\mathrm{T}}{ }^{\mathrm{b}}$ & $\mathrm{IM}$ & Tubular & $\mathrm{Fe}\left(\mathrm{C}_{5} \mathrm{H}_{7} \mathrm{O}_{2}\right)_{3}$ \\
$\mathrm{Fe}-\mathrm{M}_{\mathrm{P}}$ & $\mathrm{IS}$ & Particulate & $\mathrm{Fe}\left(\mathrm{NO}_{3} \cdot 9 \mathrm{H}_{2} \mathrm{O}\right.$ \\
$\mathrm{Mo}+\mathrm{M}_{\mathrm{P}}$ & $\mathrm{PM}$ & Particulate & $\mathrm{MoO}_{3}$ \\
$\mathrm{Mo}+\mathrm{M}_{\mathrm{T}}$ & $\mathrm{PM}$ & Tubular & $\mathrm{MoO}_{3}$
\end{tabular}

a IM: Impregnation, IS: Isomorphous substitution, PM: Physical mixture.

${ }^{\mathrm{b}}$ Methanol was used as the solvent for Iron (III) Acetylacetonate instead of water.

process, the dried template-free MCM-41 and molybdenum trioxide were carefully mixed together at room temperature and then calcined at $500^{\circ} \mathrm{C}$, as described above. The isomorphous substitution process is similar to the synthetic process for pure MCM-41, except that iron salt was added to the synthetic mixture.

\subsection{Nomenclature}

In this work, $M_{P}$ denotes pure-silica MCM-41 with the usual particulate morphology and $\mathrm{M}_{\mathrm{T}}$ denotes aluminosilicate MCM-41 with tubular morphology. Accordingly, the various notations used for the catalysts are summarized in Table 1.

\subsection{Characterization}

The powder X-ray diffraction (XRD) patterns were recorded on non-oriented samples with a Scintag $\mathrm{X} 1$ diffractometer using copper $\mathrm{K} \alpha$ radiation (wavelength $=0.154 \mathrm{~nm}$ ). Nitrogen adsorption-desorption isotherms were obtained at $77 \mathrm{~K}$ on a Micromeritics ASAP 2000 apparatus. The data were analyzed with the BET equation for surface area determination and with the BJH (Barrett-Joyner-Halenda) method for pore size distribution. The pore size distribution curves were obtained from the analysis of the desorption portion of the isotherms. Scanning electron microscopy (SEM) was performed on a Hitachi S-2400 instrument using an accelerating voltage of $20 \mathrm{keV}$, while transmission electron microscopy (TEM) was performed on a Hitachi H-7100 instrument operated at $100 \mathrm{keV}$. The temperature-programmed reduction (TPR) profiles of the catalysts were obtained with a conventional apparatus consisting of a quartz reactor. The amount of hydrogen consumed was measured with a thermal conductivity detector. The sample was heated in a flowing $10 \%$ hydrogen/nitrogen gas mixture at a rate of $10^{\circ} \mathrm{C} \mathrm{min}^{-1}$ from room temperature to $800^{\circ} \mathrm{C}$.

\subsection{Catalysis}

All the catalyst samples used in the reaction study have a metal loading of $6 \mathrm{wt} . \%$. Reactions were carried out at $500^{\circ} \mathrm{C}$ in a continuous flow micro-reactor system at atmospheric pressure. The sample was pretreated under flowing nitrogen at reaction temperature for $1 \mathrm{~h}$, and no further reductive pretreatment was performed prior to the reaction. The reaction was started by injecting the reactant, ethylbenzene, continuously $(2.72 \mathrm{ml} / \mathrm{h})$ into the nitrogen carrier gas stream (effluent flow rate $=30 \mathrm{ml} / \mathrm{min}$ ) and the reaction product (gas and liquid) was analyzed off-line by a Shimadzu GC-7A gas chromatograph. The liquid product was collected by a condenser $\left(10^{\circ} \mathrm{C}\right)$ positioned at the outlet of the reactor and the components were separated with a packed column (5\% SP- $1200+1.75 \%$ Bentone 34 on 100/120 Suplecoport, $6 \mathrm{ft}$ ). Catalyst regeneration was done at $500^{\circ} \mathrm{C}$ for 1 day under a stream of air flowing at about $75 \mathrm{ml} / \mathrm{min}$.

Total conversion of ethylbenzene is defined as the percentage of ethylbenzene converted to hydrocarbon products, while styrene selectivity is the percentage of styrene in the observed product. Both the conversion and selectivity data were based on carbon number.

\section{Results}

\subsection{X-ray diffraction (XRD)}

The XRD patterns of molybdenum oxide catalysts and their corresponding supports are presented in Fig. 1. The sample notations are listed in Table 1. The $d$-spacings $(d)$ of the first diffraction peaks are also summarized in Table 2. A small shift to lower $d$-spacing relative to the support is observed for all catalysts, showing that the perturbation effect of metal oxide on MCM-41 is not large. 


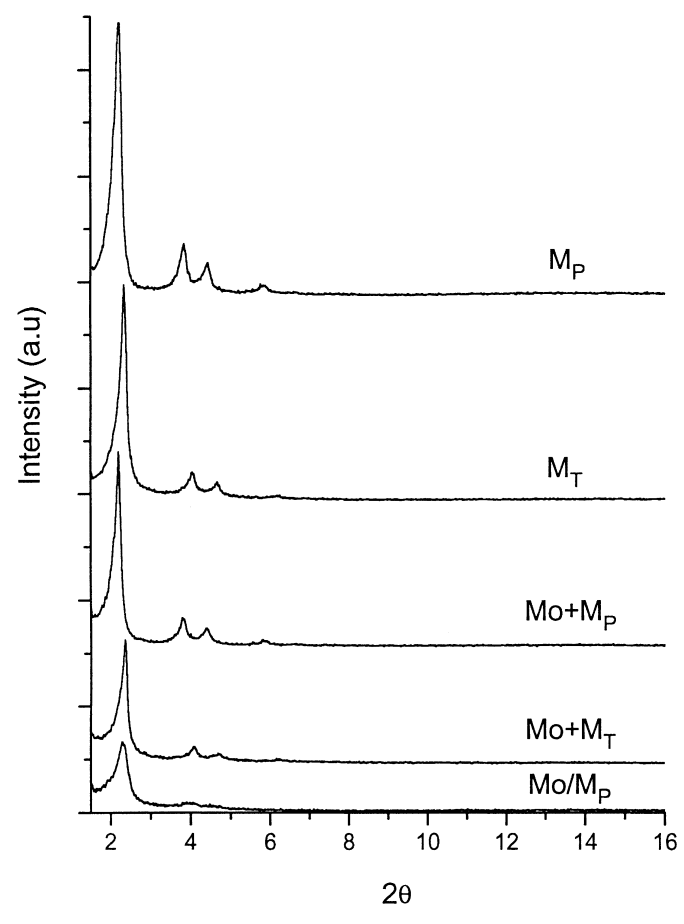

Fig. 1. XRD patterns of molybdenum oxide catalysts and supports. $\mathrm{M}_{\mathrm{P}}$ : particulate MCM-41, $\mathrm{M}_{\mathrm{T}}$ : tubular MCM-41, Mo+M $\mathrm{M}_{\mathrm{P}}$ : physically mixed catalyst with $\mathrm{M}_{\mathrm{P}}$ support, $\mathrm{Mo}+\mathrm{M}_{\mathrm{T}}$ : physically mixed catalyst with $\mathrm{M}_{\mathrm{T}}$ support, $\mathrm{Mo} / \mathrm{M}_{\mathrm{P}}$ : impregnated catalyst with $\mathrm{M}_{\mathrm{P}}$ support.

The pristine $\mathrm{MCM}-41$ supports $\left(\mathrm{M}_{\mathrm{P}}\right.$ and $\mathrm{M}_{\mathrm{T}}$ ) show five XRD peaks, indicating structural regularity. They have higher thermal and hydrothermal stability than

Table 2

Characterization of catalysts

\begin{tabular}{llllll}
\hline Catalyst & $d(\AA)$ & $S / \mathrm{A}\left(\mathrm{m}^{2} / \mathrm{g}\right)$ & $P / \mathrm{V}(\mathrm{ml} / \mathrm{g})^{\mathrm{a}}$ & $P / \mathrm{D}(\AA)$ & $W / \mathrm{T}(\AA)^{\mathrm{b}}$ \\
\hline $\mathrm{M}_{\mathrm{P}}$ & 40.4 & 1051 & 0.93 & 27 & 20 \\
$\mathrm{M}_{\mathrm{T}}$ & 37.8 & 1123 & 1.05 & $25 \& 37$ & 19 \\
$\mathrm{Mo} / \mathrm{M}_{\mathrm{P}}$ & 38.4 & 779 & 0.50 & 24 & 20 \\
$\mathrm{Mo} / \mathrm{SiO}_{2}$ & - & 377 & 0.70 & 55 & - \\
$\mathrm{NaMo} / \mathrm{M}_{\mathrm{P}}$ & - & 154 & 0.16 & 80 & - \\
$\mathrm{Mo}+\mathrm{M}_{\mathrm{P}}$ & 39.8 & 959 & 0.81 & 27 & 19 \\
$\mathrm{Mo}+\mathrm{M}_{\mathrm{T}}$ & 37.3 & 1005 & 0.88 & $24 \& 37$ & 19 \\
$\mathrm{Mo}+\mathrm{M}_{\mathrm{T}}{ }^{\mathrm{c}}$ & 36.7 & 958 & 0.78 & $23 \& 37$ & 19 \\
$\mathrm{Fe} / \mathrm{M}_{\mathrm{P}}$ & 38.3 & 774 & 0.53 & 25 & 19 \\
$\mathrm{Fe} / \mathrm{M}_{\mathrm{T}}$ & 36.2 & 918 & 0.84 & $24 \& 37$ & 18 \\
$\mathrm{Fe}-\mathrm{M}_{\mathrm{P}}$ & 37.3 & 943 & 0.71 & $23 \& 37$ & 20
\end{tabular}

${ }^{\text {a }}$ Cumulative values for pore diameter between 10 and $100 \AA$ ${ }^{\mathrm{b}} W / \mathrm{T}=\left[2 d /(3)^{1 / 2}\right]-P / \mathrm{D}$

${ }^{\mathrm{c}}$ Mo metal loading is $9 \mathrm{wt} . \%$ instead of $6 \mathrm{wt} . \%$ in other catalysts. the usual MCM-41 synthesized by the normal basic solution route. Their XRD patterns were not affected significantly even after these samples were heated in air at $800^{\circ} \mathrm{C}$ or in boiling water for at least 1 day. We have attributed this behavior to the thicker wall $(2.0 \mathrm{~nm})$ of MCM-41 obtained in our delayed neutralization method [23].

The physically mixed MCM-41-supported molybdenum oxide catalysts $\left(\mathrm{Mo}+\mathrm{M}_{\mathrm{P}}\right.$ and $\left.\mathrm{Mo}+\mathrm{M}_{\mathrm{T}}\right)$ preserve much of the periodic structure of MCM-41, while the impregnated catalyst $\left(\mathrm{Mo} / \mathrm{M}_{\mathrm{P}}\right)$ suffers a drastic decrease in the diffraction peak intensities. In addition, the resolution of the higher order peaks of $\mathrm{Mo} / \mathrm{M}_{\mathrm{P}}$ becomes very poor. The situation is even more serious with sodium molybdate precursor $\left(\mathrm{NaMo} / \mathrm{M}_{\mathrm{P}}\right)$, whereby the structure of MCM-41 collapsed altogether (not shown). Silica-supported catalyst $\left(\mathrm{Mo} / \mathrm{SiO}_{2}\right)$ is also amorphous in nature.

Similar XRD patterns to $\mathrm{Mo} / \mathrm{M}_{\mathrm{P}}$ were observed in the corresponding impregnated iron oxide catalyst. However, the peak intensity of $\mathrm{Fe} / \mathrm{M}_{\mathrm{T}}$ is slightly higher, since methanol instead of water is used as the solvent during the impregnation process. Interestingly, iron-substituted MCM-41 catalyst (Fe-M $\left.\mathrm{M}_{\mathrm{P}}\right)$ also has low peak intensities.

Except $\mathrm{NaMo} / \mathrm{M}_{\mathrm{P}}$, no other catalyst showed any diffraction peaks from the supported metal oxide phase. We do not identify the molybdenum species in $\mathrm{NaMo} / \mathrm{M}_{\mathrm{P}}$ since it is not the prime catalyst of interest in this study.

The crystallinity of the used catalysts was also checked by XRD. After two cycles of reaction, these catalysts still retained at least half of their original peak intensity, even though the quality of the used catalyst samples is poorer than that of the fresh catalysts.

\subsection{Surface area and porosity}

Table 2 lists the surface area $(S / A)$, pore volume $(P / \mathrm{V})$, pore diameter $(P / \mathrm{D})$, and wall thickness $(W / \mathrm{T})$ of the catalysts and supports. A selection of their nitrogen adsorption-desorption isotherms is also presented in Fig. 2.

In accordance with XRD results, physically mixed catalysts with structural integrity retained much of the surface area and pore volume of MCM-41. The small reduction in pore size relative to MCM-41 

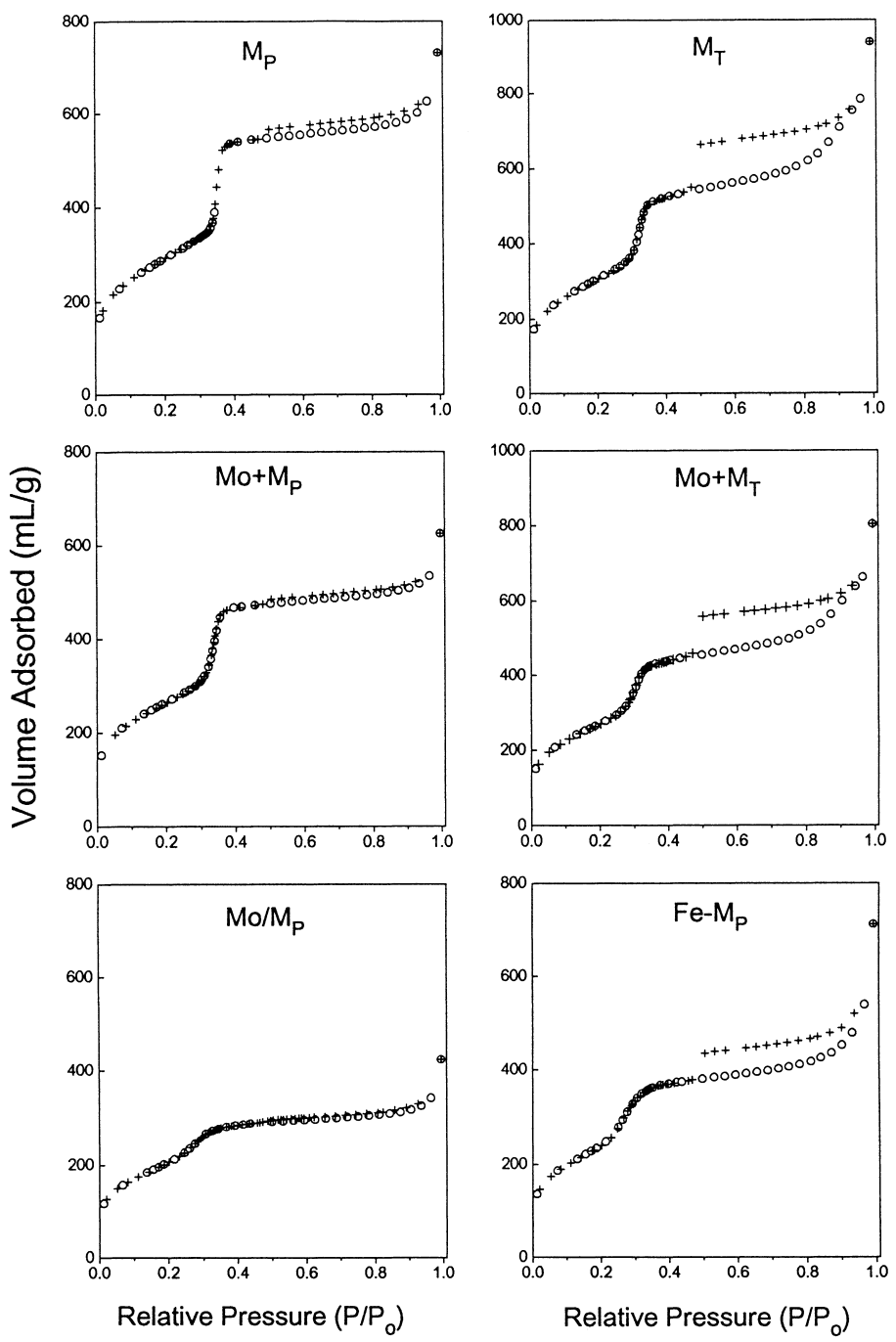

Fig. 2. Nitrogen adsorption-desorption isotherms of molybdenum and iron oxide catalysts and supports. Top curve (desorption), Bottom curve (adsorption). Fe-MP: iron substituted MCM-41 catalyst. Other catalyst notations are similar to those used in Fig. 1.

suggests that the metal oxide in the channel system is probably close to a monolayer. The impregnated catalysts, which show partial structural collapse, have lower surface area and pore volume. They also show a larger reduction in pore size than physically mixed catalysts. The situation can be improved significantly by using organic solvent, as mentioned before. Not surprisingly, amorphous $\mathrm{Mo} / \mathrm{SiO}_{2}$ and $\mathrm{NaMo} / \mathrm{M}_{\mathrm{P}}$ samples have very low surface areas. One should note that the surface areas and pore volumes of samples in tubular MCM-41 series are consistently higher than those samples in particulate MCM-41 series.

All the nitrogen adsorption-desorption isotherms in Fig. 2 show an inflection near $p / p_{0}=0.34$ characteristic of the well-known capillary condensation in MCM-41. The adsorption isotherm above $p / p_{0}=0.8$ shows the standard multilayer condensation to macroscopic saturation. Again, the physically mixed samples give sharper inflections than impregnated ones, indicating more uniform pore-size distributions, i.e. preserving the structure better. One striking behavior 
in Fig. 2 that we have observed is a distinct second inflection in the desorption isotherm at about $p / p_{0}=0.5$ for all tubular samples, and a large hysteresis in the isotherm. This indicates that a second pore system of larger pore size is present in tubular MCM-41, according to the capillary condensation model. The size of the inflections reflects the relative amount of this large pores (which we tentatively called pore defects) and its concentration seems to depend directly on the amount of hole defects in the tubules (see TEM). Previously, Chao and coworkers [32] have indicated slit-like defects as a possibility in interpreting the hysteresis in their nitrogen adsorption-desorption isotherms at a much higher pressure $\left(p / p_{0}>0.9\right)$, but macropores are probably the cause. Until now, the true origin of such pore defects and hysteresis is not clear and further study is required.

Interestingly, the Fe- $\mathrm{M}_{\mathrm{P}}$ sample also shows this hysteresis behavior. This result suggests that the $37 \AA$ pore defects are related to the presence of heteroatoms (aluminum or iron) in MCM-41, and the defects are formed after removing these atoms from the wall between neighboring channels e.g. via a dealumination process during the template removal process. In a series of MCM-41 tubules with different pore sizes, we found that the position of the inflection in the adsorption-desorption isotherm which corresponds to this defect remained unchanged.

\subsection{Temperature-programmed reduction $(T P R)$}

Fig. 3 shows the TPR profiles of various MCM-41 and silica-supported molybdenum oxide catalysts. Reduction of molybdenum oxide on physically mixed catalysts seems to begin at a lower temperature than the impregnated ones. The reduction process of all catalysts covers a broad range of temperatures. Only in the case of heptamolybdate impregnated samples is a low temperature peak resolved. The plateaus observed with $\mathrm{Mo}+\mathrm{M}_{\mathrm{T}}$ and $\mathrm{Mo}+\mathrm{M}_{\mathrm{P}}$ catalysts are not due to artifacts, such as the limitation in hydrogen concentration, since they are far below the maximum peak intensity recorded. Qualitatively, physically mixed Mo+ $\mathrm{M}_{\mathrm{T}}$ catalyst consumed the most hydrogen, whereas the impregnated $\mathrm{Mo} / \mathrm{M}_{\mathrm{P}}$ catalyst consumed the least. For the catalysts with particulate MCM-41 support, a second stage of reduction is observed at temperatures beyond $700^{\circ} \mathrm{C}$.

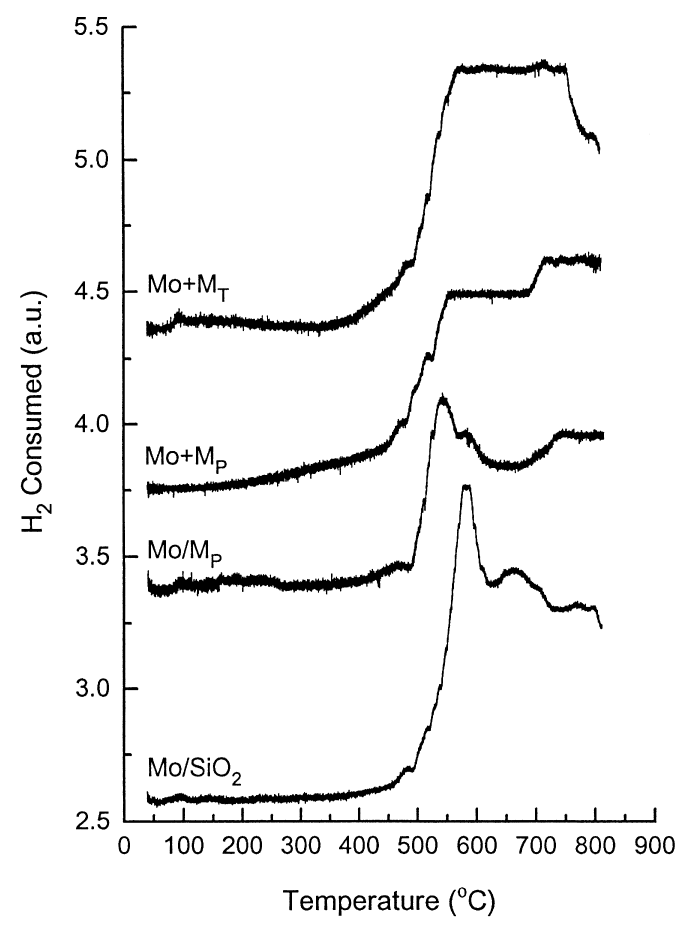

Fig. 3. TPR profiles of molybdenum oxide catalysts. $\mathrm{Mo} / \mathrm{SiO}_{2}$ : impregnated catalyst with silica support. Other catalyst notations are similar to those used in Fig. 1.

\subsection{Electron microscopy}

SEM micrographs of the two different preparations of MCM-41 have been previously examined and will not be reproduced here [23]. In tubular MCM-41, the tubules has quite uniform diameter of less than $1 \mu \mathrm{m}$ and they are well dispersed individually. In particulate MCM-41, the micro-particles (diameter $\approx 0.5 \mu \mathrm{m}$ ) agglomerate into larger particles of $1-3 \mu \mathrm{m}$ in size. Fig. 4 shows the TEM picture of tubular MCM-41 after calcination. A similar picture is obtained for as-synthesized sample. Extensive structural defects can be seen as white spots, whereas the framework of particulate MCM-41 remains mostly intact (picture not shown). The existence of such hole defects is further clarified by taking TEM pictures on ultrathin sections of the tubules.

In conclusion, there are two types of structural defect observed in tubular MCM-41: the pore defects at $\sim 37 \AA$ (from nitrogen adsorption-desorption isotherm) of unknown origin and the hole defects in 


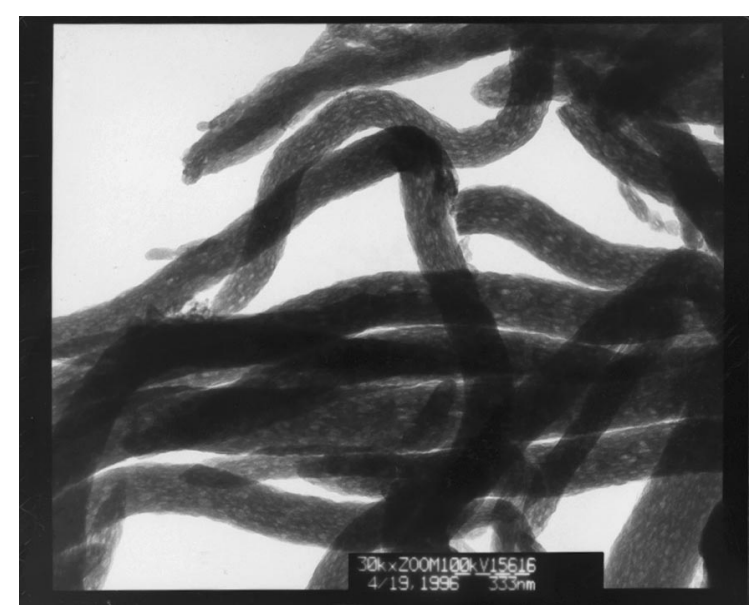

Fig. 4. TEM micrograph of tubular MCM-41. The many white dots on the tubules indicate hole defects.

the order of $200 \AA$ (from TEM). The former is not clearly visible even under micrographs taken with microtome TEM technique. It is possible that the latter is formed from the local collapse of pore walls, and thus increases the porosity of tubular MCM-41. Also, the holes can act as reservoirs connecting neighboring uni-dimensional channels. These two types of defect contribute appreciably to the total pore volume of tubular MCM-41. Knowing the total nitrogen adsorption capacity of the sample, and taking the adsorption capacity beyond $40 \AA$ as from holes (judging from the pore-size distribution plot), we can estimate the relative contribution of pore and hole defects to the total pore volume. The hole defects contribute $\sim 12 \%$ of the total pore volume $(1.12 \mathrm{ml} / \mathrm{g}$, pore diameter ranging from 11 to $300 \AA$ ), as compared to $\sim 35 \%$ contributed by the pore defects.

\subsection{Ethylbenzene dehydrogenation reaction}

The catalytic performances of various molybdenum oxide-loaded catalysts at $500^{\circ} \mathrm{C}$ are compared in Fig. 5. Regenerated catalysts also showed similar trends of reaction.

The catalytic activity usually decreases steadily with increasing time-on-stream. The styrene selectivity over physically mixed $\mathrm{Mo}+\mathrm{M}_{\mathrm{T}}$ catalyst with aluminosilicate framework tends to increase slightly with increasing time-on-stream, whereas it is quite

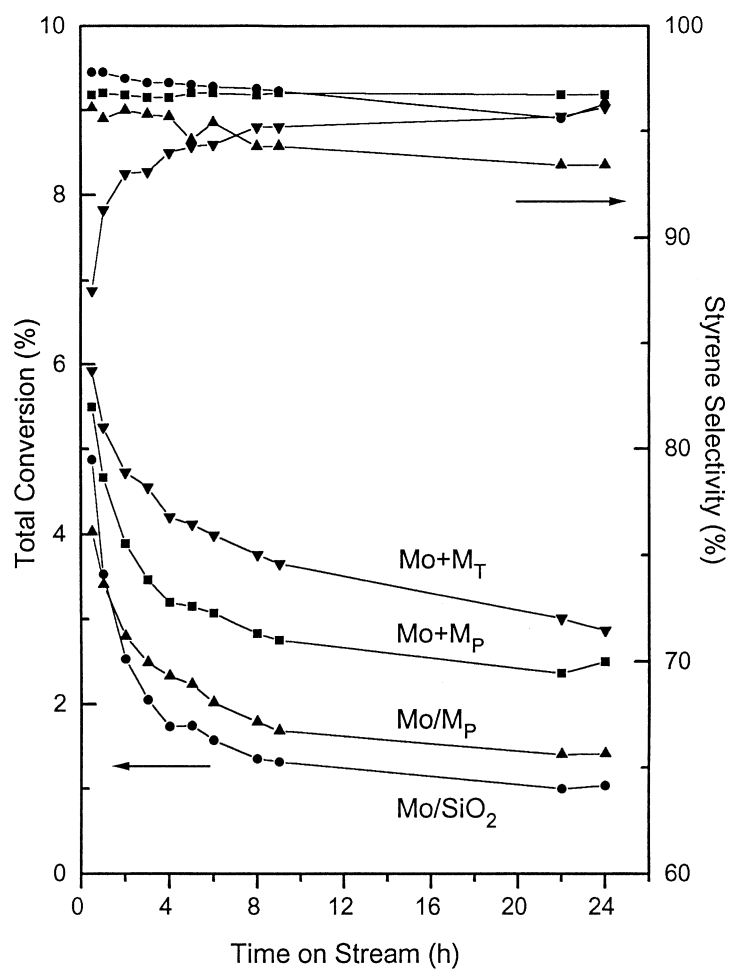

Fig. 5. Variation of total conversion of ethylbenzene (bottom) and selectivity of styrene (top) with reaction time-on-stream over various molybdenum oxide catalysts. Catalyst notations are similar to those used in Fig. 3.

stable in the case of Mo+M $\mathrm{M}_{\mathrm{P}}$ catalyst with non-acidic silica framework. Generally, the selectivity of styrene, which is the major product, is at least $90 \%$ at steady state. Minor products include benzene and toluene, with less than $1 \%$ of light hydrocarbons.

In both fresh and regenerated catalysts, physically mixed catalysts gave higher activity than impregnated ones after $24 \mathrm{~h}$ of reaction, and MCM-41-supported catalysts are better than amorphous silica-supported ones. Physically mixed molybdenum oxide catalysts with tubular MCM-41 support are particularly active. The activity decreases in the order : $\mathrm{Mo}+\mathrm{M}_{\mathrm{T}}>\mathrm{Mo}+\mathrm{M}_{\mathrm{P}}>\mathrm{Mo} / \mathrm{M}_{\mathrm{P}}>\mathrm{Mo} / \mathrm{SiO}_{2}$. Interestingly, the rate of deactivation also seems to depend on the nature of the support, and increases in the order : $\mathrm{M}_{\mathrm{T}}<\mathrm{M}_{\mathrm{P}}<\mathrm{SiO}_{2}$.

Table 3 compares the product distribution of physically mixed $\mathrm{Mo}+\mathrm{M}_{\mathrm{T}}$ and $\mathrm{Mo}+\mathrm{M}_{\mathrm{P}}$ catalysts. The data from pure MCM-41 are also included as reference. One can see that styrene selectivity over $\mathrm{Mo}+\mathrm{M}_{\mathrm{T}}$ is 
Table 3

Product distribution of physically mixed molybdenum oxide catalysts and supports

\begin{tabular}{|c|c|c|c|c|c|c|c|c|}
\hline & \multicolumn{2}{|c|}{$\mathrm{Mo}+\mathrm{M}_{\mathrm{P}}$} & \multicolumn{2}{|l|}{$\mathrm{M}_{\mathrm{P}}$} & \multicolumn{2}{|c|}{$\mathrm{Mo}+\mathrm{M}_{\mathrm{T}}$} & \multicolumn{2}{|l|}{$\mathbf{M}_{\mathrm{T}}$} \\
\hline & $0.5 \mathrm{~h}$ & $24 \mathrm{~h}$ & $0.5 \mathrm{~h}$ & $6 \mathrm{~h}$ & $0.5 \mathrm{~h}$ & $24 \mathrm{~h}$ & $0.5 \mathrm{~h}$ & $24 \mathrm{~h}$ \\
\hline $\begin{array}{l}\text { Total Conv. } \\
\text { Selectivity }\end{array}$ & 5.50 & 2.50 & 0.18 & 0.18 & 5.93 & 2.87 & 0.67 & 0.40 \\
\hline $\mathrm{LH}^{\mathrm{a}}$ & 0.2 & 0.3 & 2.6 & 2.7 & 0.3 & 0.4 & 9.4 & 6.2 \\
\hline Benzene & 1.0 & 1.1 & 11.1 & 10.0 & 4.8 & 1.9 & 52.1 & 44.2 \\
\hline Toluene & 1.9 & 2.3 & 4.7 & 4.6 & 2.4 & 1.5 & 2.3 & 3.8 \\
\hline Xylene & 0 & 0 & 0 & 0 & 0 & 0 & 2.9 & 0 \\
\hline Styrene & 96.4 & 96.4 & 81.5 & 79.3 & 87.3 & 95.7 & 25.2 & 43.2 \\
\hline $\mathrm{DEB}^{\mathrm{b}}$ & 0 & 0 & 0 & 0 & 0 & 0 & 5.7 & 0 \\
\hline $\mathrm{PH}^{\mathrm{c}}$ & 0.4 & 0 & 0 & 3.3 & 5.1 & 0.6 & 2.3 & 2.6 \\
\hline
\end{tabular}

${ }^{a}$ LH: Light hydrocarbon.

b DEB: Diethylbenzene.

${ }^{\mathrm{c}} \mathrm{PH}$ : Polyaromatic hydrocarbon.

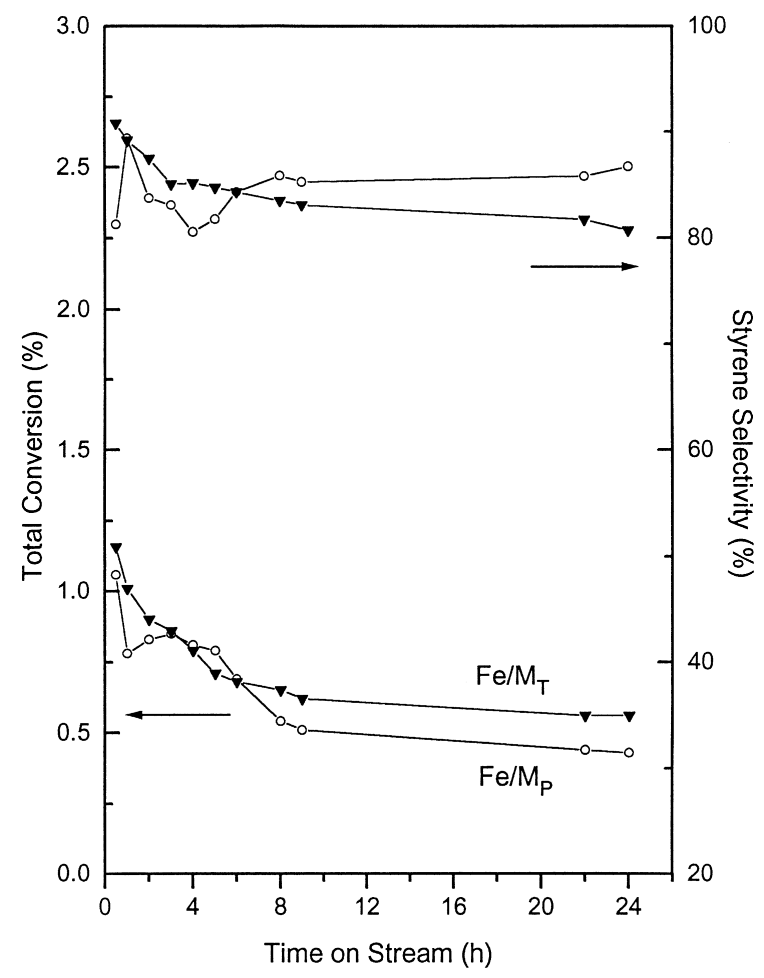

Fig. 6. Variation of total conversion of ethylbenzene (bottom) and selectivity of styrene (top) with reaction time-on-stream over impregnated iron oxide catalysts with particulate MCM-41 (Fe/MP) and tubular MCM-41 (Fe/M $\left.\mathrm{M}_{\mathrm{T}}\right)$ supports. lower than $\mathrm{Mo}+\mathrm{M}_{\mathrm{P}}$ at the initial stage $(0.5 \mathrm{~h})$ of reaction. At this stage, much larger amounts of benzene and polyaromatic hydrocarbon are observed in the product. It is important to note that the yield of styrene and toluene is very much improved in the catalysts relative to the support. The yield of light hydrocarbon and benzene also increases slightly in $\mathrm{Mo}+\mathrm{M}_{\mathrm{P}}$ catalyst but decreases in $\mathrm{Mo}+\mathrm{M}_{\mathrm{T}}$ catalyst, with reference to their respective support.

When sodium molybdate was used as the precursor, the activity and styrene selectivity of the $\mathrm{NaMo} / \mathrm{M}_{\mathrm{P}}$ catalyst are the lowest.

Iron-based catalysts do not perform as well as molybdenum-based catalysts. The performance of impregnated $\mathrm{Fe} / \mathrm{M}_{\mathrm{P}}$ and $\mathrm{Fe} / \mathrm{M}_{\mathrm{T}}$ catalysts is compared in Fig. 6. A sample of $\mathrm{Fe} / \mathrm{M}_{\mathrm{P}}$ catalyst was also studied, as shown in Fig. 7. Impregnated $\mathrm{Fe} / \mathrm{M}_{\mathrm{P}}$ catalyst performed better than substituted $\mathrm{Fe} / \mathrm{M}_{\mathrm{P}}$ catalyst but the activity of the latter decays much less rapidly than the former.

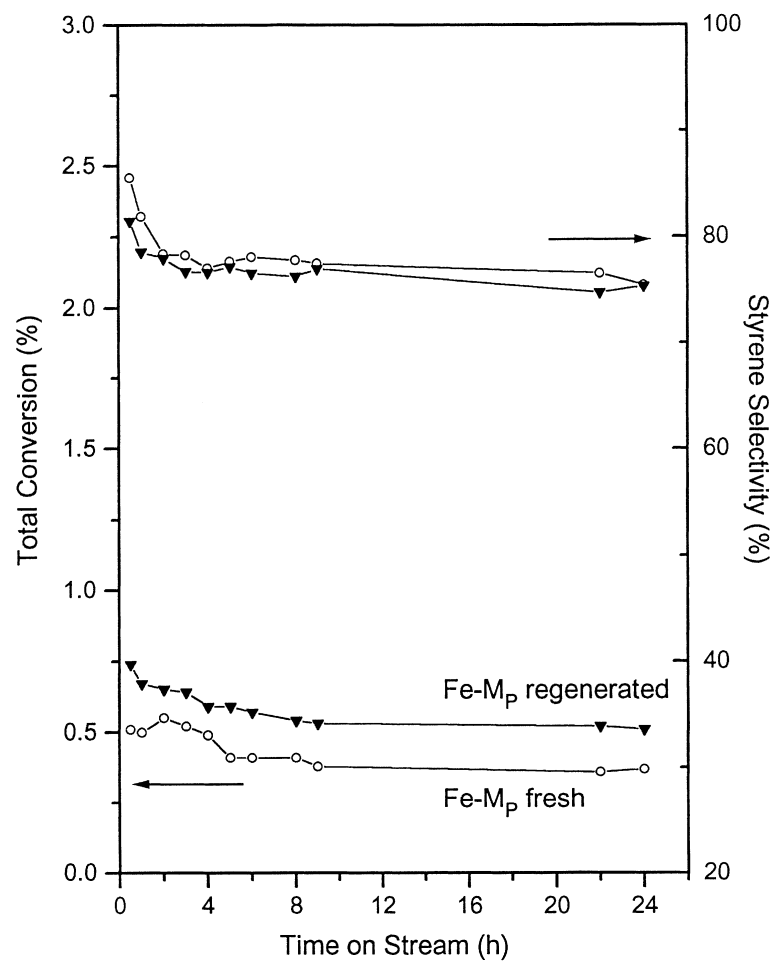

Fig. 7. Variation of total conversion of ethylbenzene (bottom) and selectivity of styrene (top) with reaction time-on-stream over fresh and regenerated iron substituted MCM-41 catalysts. 
Fluctuations of initial conversion are observed in fresh iron oxide catalysts, but they are much less prominent in regenerated catalysts. We thought that this phenomenon might be related to the reductive disintegration of large iron oxide particles under the reducing environment of the reacting mixture. A similar phenomenon is also observed in molybdenum-based catalysts, but at a lower temperature of $400^{\circ} \mathrm{C}$. Therefore, the catalytic performances of supported iron oxide catalysts were compared only at longer times-on-stream.

\section{Discussion}

\subsection{Characteristic of tubular MCM-41}

The details regarding the synthesis and structural morphology of tubular MCM-41 have been described previously $[22,23,30]$. Although particulate and tubular MCM-41 have different morphologies, their pore structures are similar, as can be verified by comparing their XRD patterns, TEM micrographs and pore size distributions.

Our tubular MCM-41 represents a unique family of MCM-41 with a large degree of structural defects, which result in large pores (nitrogen adsorption-desorption isotherm) and holes (TEM). The former are of unknown origin while the latter probably arise from the local collapse of channel walls and were found to distribute throughout the framework. The hysteresis portion in the adsorption-desorption isotherm at $p / p_{0}>0.8$ is most likely due to these holes in the order of $200 \AA$ [33]. The presence of these defects probably made the channels in tubular MCM-41 interconnected into a three-dimensional system.

Even though structural defects are present in tubular MCM-41, its structure still remained intact after thermal treatment at $560^{\circ} \mathrm{C}$ during the template removal process. Its surface area and pore volume are comparable to those of particulate MCM-41. Moreover, SEM and TEM results also confirm the stability of our materials. Coustel et al. [34] have studied the relationship of wall thickness versus thermal and hydrothermal stabilities and found that a wall thickness of $16 \AA$ can preserve the original mesopore volume after the stability test. Therefore, the high thermal and hydrothermal stabilities of our particulate and tubular MCM-41 made from the delayed neutralization process are probably due to their thicker channel walls ( 20 А).

\subsection{Nature of catalyst}

Tubular MCM-41 can behave differently depending on the method of catalyst preparation. In the preparation of physically mixed catalysts, it is generally agreed that many oxides, such as molybdenum trioxide, can disperse spontaneously on the surface of a support after thermal treatment to form monolayers. This is because a monolayer is a thermodynamically stable form in these cases $[35,36]$. In order to minimize the formation of multilayers, the molybdenum metal loading of the catalysts is limited to $6 \mathrm{wt} . \%$, which is even below the critical dispersion capacity for a monolayer of molybdenum trioxide on the surface of silica. Consistently, XRD analysis does not reveal the existence of bulk molybdenum trioxide on the surface of any catalyst.

Characterization of the physically mixed $\mathrm{Mo}+\mathrm{M}_{\mathrm{T}}$ catalysts shows that they still preserve the basic properties of the support, namely bimodal pore size distribution, high surface area and pore volume. In other words, tubular MCM-41 is stable to thermal treatment in the presence of transition metal cations to at least $500^{\circ} \mathrm{C}$. The presence of metal oxide in the mesopore system of these physically mixed catalysts can be concluded from the decreased pore volume relative to the support. Also, the high temperature treatment in catalyst preparation leads to some channel disorder as is evident from the decreased XRD peak intensities.

The catalyst prepared by solution impregnation showed severe collapse in structure. This effect is due mostly to the basic nature of the impregnation solution, which causes the dissolution of the silica framework. However, this situation can be improved significantly by using organic solvent. Therefore, physical mixing is a better method of catalyst preparation in this case.

The TPR profiles of our impregnated catalysts are similar to those reported by Ismail et al. [37] and López Cordero et al. [38]. Broad peaks are observed between 400 and $800^{\circ} \mathrm{C}$. As was already pointed out by Thomas et al. [39], highly dispersed monolayer-type catalysts at low molybdenum oxide 
contents often show broad TPR peaks, whereas bulk compounds in general show sharp TPR peaks. The explanation given is that the support material usually exhibits heterogeneity causing a spectrum of activation energies for reduction of compounds adsorbed on these sites. A distinct peak can be seen in the profiles of impregnated catalysts since the monolayers formed from heptamolybdate precursor are smaller and are more uniform in size. The monolayers on the surface of physically mixed catalysts derived from thermal spreading of molybdenum trioxide are much larger. A possible explanation for the plateau is provided by assuming that the increased rate of hydrogen consumption at increasing reduction temperatures is roughly compensated by the decrease in the active surface area of fresh molybdenum oxide. Physically mixed $\mathrm{Mo}+\mathrm{M}_{\mathrm{P}}$ catalyst seems to have more multilayers than $\mathrm{Mo}+\mathrm{M}_{\mathrm{T}}$, judging from the increase in reduction temperature beyond $700^{\circ} \mathrm{C}$. This observation is in-line with the observed increases in peak intensity around this temperature with increasing molybdenum oxide content on silica [39]. The finding above could be explained by the better transport of material in the highly porous tubular MCM-41 during catalyst preparation.

\subsection{Catalytic study}

The catalytic performance of various molybdenum oxide catalysts was tested with ethylbenzene dehydrogenation. The results are compared in Table 4 . We have found that physical mixing is the simplest and best way to prepare a transition metal oxide-loaded catalyst, so we focus mainly on the comparison of $\mathrm{Mo}+\mathrm{M}_{\mathrm{T}}$ and $\mathrm{Mo}+\mathrm{M}_{\mathrm{P}}$ catalysts. It can be seen that $\mathrm{Mo}+\mathrm{M}_{\mathrm{T}}$ is the best performing catalyst with the highest activity after $24 \mathrm{~h}$ of reaction and has the lowest decay rate.

The decay rate of $\mathrm{Mo}+\mathrm{M}_{\mathrm{T}}$ catalyst is the lowest even under the influence of intense Brönsted acid-catalyzed side reactions known to produce coke, i.e. oligomerization of styrene and cracking of ethylbenzene, which tend to deactivate the catalyst. This is just the opposite of what we observed. Therefore, aluminum is unlikely to play a significant role in promoting the catalytic effect in $\mathrm{Mo}+\mathrm{M}_{\mathrm{T}}$ catalyst. Obviously, the high porosity of its tubular support has played an important role in minimizing catalyst deactivation. In addition, the high catalytic activity of $\mathrm{Mo}+\mathrm{M}_{\mathrm{T}}$ catalyst may be due to its high porosity as well.

Anyway, the presence of defects in tubular MCM-41 might have the following advantages for catalyst preparation and reaction:

1. Each segment of the tubule's wall can be considered as a small particle of MCM-41. With the help of defects, diffusion of reactant and product could proceed across instead of just along the channels in particulate MCM-41. It is also possible that the large internal channel at the center of the tubule is freely accessible to reactant and product. In this way, we have a two-way diffusion system, which can minimize traffic congestion. This kind of improved diffusion system make the catalyst less susceptible to coking and deactivation. Besides, the faster removal of product away from the active sites can shift the equilibrium of the reaction to the right, thereby increasing the conversion of ethylbenzene.

2. The presence of defects allows a better spreading of molybdenum trioxide from the external surface of tubule into its internal pore structure.

Table 4

Catalytic performance of molybdenum oxide catalysts ${ }^{\mathrm{a}}$

\begin{tabular}{|c|c|c|c|c|c|c|c|}
\hline \multirow[t]{3}{*}{ Catalyst } & \multirow[t]{3}{*}{ S/A $\left(\mathrm{m}^{2} / \mathrm{g}\right)$} & \multirow{2}{*}{\multicolumn{2}{|c|}{$\%$ Decay }} & \multicolumn{4}{|c|}{ Activity $\left(10^{-3} \mathrm{~mol} / \mathrm{hg}\right)$} \\
\hline & & & & \multicolumn{2}{|l|}{$0.5 \mathrm{~h}$} & \multicolumn{2}{|l|}{$24 \mathrm{~h}$} \\
\hline & & Fresh & Regenerated & Fresh & Regenerated & Fresh & Regenerated \\
\hline $\mathrm{Mo}+\mathrm{M}_{\mathrm{T}}$ & 1005 & 20 & 18 & 6.34 & 5.37 & 3.07 & 2.99 \\
\hline $\mathrm{Mo}+\mathrm{M}_{\mathrm{P}}$ & 959 & 29 & 31 & 5.88 & 5.08 & 2.60 & 2.20 \\
\hline $\mathrm{Mo} / \mathrm{M}_{\mathrm{P}}$ & 779 & 31 & 22 & 4.34 & 4.04 & 1.53 & 1.48 \\
\hline $\mathrm{Mo} / \mathrm{SiO}_{2}$ & 377 & 48 & 47 & 5.26 & 4.74 & 1.12 & 0.93 \\
\hline
\end{tabular}

${ }^{\mathrm{a}}$ The rate of catalyst deactivation is expressed in terms of the percentage decrease in initial conversion after $2 \mathrm{~h}$ of reaction. 
The concentration of reactive centers (possibly pairs of neighboring molybdenum cations) thus increases, as demonstrated by TPR. This suggestion is consistent with the reaction model proposed by Chen et al. [40] involving pairs of neighboring metal active sites, one for adsorption of phenyl ring and the other for dehydrogenation of alkyl chain alongside with the lattice oxygen of molybdenum oxide. The very low activity of $\mathrm{NaMo} / \mathrm{M}_{\mathrm{P}}$ catalyst can be partly explained by the absence of these paired centers. Unlike molybdenum trioxide or heptamolybdate anions, where the basic $\mathrm{MoO}_{6}$ octahedra are held together through edge-sharing interactions, the layer-like structure of sodium molybdate with its molydate tetrahedra connected by interlinking sodium cations as well as by hydrogen-bonding may tend to form monoatomic centers on $\mathrm{NaMo} / \mathrm{M}_{\mathrm{P}}$ catalyst [41].

3. The presence of defects allows a better spreading of the reduced molybdenum oxide species formed during the course of reaction through its entire surface, thus lowering the possibility of sintering in a reduced environment. Here, we see that the decay rate is highest in $\mathrm{Mo} / \mathrm{SiO}_{2}$ catalyst, since it is amorphous and has the lowest surface area.

The performance of iron-based catalysts is always lower than that of molybdenum-based catalysts. If the rate-determining step of this reaction is the heterolytic dissociation of the alkyl C-H bond, then it is tempting to ascribe the lower activity of iron-based catalysts to the lower average oxidation states of iron, i.e. smaller electrostatic field around the iron active sites. Comparing the performance of impregnated $\mathrm{Fe} / \mathrm{M}_{\mathrm{T}}$ and $\mathrm{Fe} / \mathrm{M}_{\mathrm{P}}$ catalysts (see Fig. 6) shows again that the tubular sample gives a higher activity. However, in the particulate sample, there are structural changes of the support in catalyst preparation. The effect of the support in this case is less trivial. One needs further studies. We also observed that the ethylbenzene dehydrogenation activity is even lower in Fe-M catalyst with a similar bimodal pore size distribution. In impregnated catalysts, some of the extra-framework iron species might have migrated to the framework positions during catalyst preparation or reaction at $500^{\circ} \mathrm{C}$. Judging from the poor catalytic performance of Fe-M catalyst, one sees that this phenomenon can cause a loss of catalytic activity in the impregnated catalysts and can also interfere with the effects of a pore system.

\section{Conclusion}

Mesoporous MCM-41 is a very interesting catalyst support due to its large surface area and pore size. We have presented results from nitrogen adsorption-desorption experiments and TEM studies to conclude that the tubular MCM-41 has structural defects. These defects might facilitate the diffusion of reactant and product and lead to better catalytic performance. This reaction approaches equilibrium easily; thus, the diffusion of product away from the reaction sites is important in determining conversion. The use of a relatively small reacting molecule like ethylbenzene can eliminate any geometrical or shape effect of the channels on the diffusion of reactant. Therefore, correlating the increased catalytic performance of $\mathrm{Mo}+\mathrm{M}_{\mathrm{T}}$ catalysts with the improved inter-channel diffusion seems reasonable. This structural effect should be generally applicable to many other catalytic reaction systems. Further study on the morphological effect of MCM-41 on catalytic performance should be very interesting.

\section{Acknowledgements}

We are grateful for discussions with Profs. S.B. Liu, B.-Z. Wan and S. Cheng. This research was supported by the China Petroleum Co. and the National Science Council of Taiwan.

\section{References}

[1] C.T. Kresge, M.E. Leonowicz, W.J. Roth, J.C. Vartuli, J.S. Beck, Nature 359 (1992) 710.

[2] J.S. Beck, J.C. Vartuli, W.J. Roth, M.E. Leonowicz, C.T. Kresge, K.D. Schmitt, C.T-W. Chu, D.H. Olson, E.W. Sheppard, S.B. McCullen, J.B. Higgins, J.L. Schlenker, J. Am. Chem. Soc. 114 (1992) 10834.

[3] C.T. Kresge, D.O. Marler, G.S. Rav, B.H. Rose, US Patent 5366945 (1994) to Mobil Oil Corporation.

[4] A. Sayari, Chem. Mater. 8 (1996) 1840.

[5] P.B. Venuto, Stud. Surf. Sci. Catal. 105 (1997) 811.

[6] A. Corma, Chem. Rev. 97 (1997) 2373.

[7] D.J. Macquarrie, D.B. Jackson, Chem. Commun. (1997) 1781

[8] W.M. Van Rhijn, D.E. De Vos, B.F. Sels, W.D. Bossaert, P.A. Jacobs, Chem. Commun. (1998) 317.

[9] Q. Huo, D.I. Margolese, U. Ciesla, D.G. Demuth, P. Feng, T.E. Gier, P. Sieger, A. Firouzi, B.F. Chmelka, F. Schüth, G.D. Stucky, Chem. Mater. 6 (1994) 1176. 
[10] C-G. Wu, T. Bein, Science 264 (1994) 1757.

[11] C-G. Wu, T. Bein, Chem. Mater. 6 (1994) 1109.

[12] A. Corma, V. Fornés, H. García, M.A. Miranda, M.J. Sabater, J. Am. Chem. Soc. 116 (1994) 9767.

[13] T. Shinoda, Y. Izumi, M. Onaka, J. Chem. Soc., Chem. Commun. (1995) 1801.

[14] Q. Huo, D.I. Margolese, G.D. Stucky, Chem. Mater. 8 (1996) 1147.

[15] N.K. Raman, M.T. Anderson, C.J. Brinker, Chem. Mater. 8 (1996) 1682.

[16] A. Cauvel, D. Brunel, F. Di Renzo, E. Garrone, B. Fubini, Langmuir 13 (1997) 2773.

[17] H. Kosslick, G. Lischke, G. Walther, W. Storek, A. Martin, R. Fricke, Microporous Mater. 9 (1997) 13.

[18] C.P. Jaroniec, M. Kruk, M. Jaroniec, A. Sayari, J. Phys. Chem. B 102 (1998) 5503.

[19] R. Ryoo, S. Jun, J. Phys. Chem. B 101 (1997) 317.

[20] L. Chen, T. Horiuchi, T. Mori, K. Maeda, J. Phys. Chem. B 103 (1999) 1216

[21] K.A. Koyano, T. Tatsumi, Y. Tanaka, S. Nakata, J. Phys. Chem. B 101 (1997) 9436.

[22] H.P. Lin, C.Y. Mou, Science 273 (1996) 765.

[23] H.P. Lin, S. Cheng, C.Y. Mou, Microporous Mater. 10 (1997) 111.

[24] K.K. Kearby, in: P.H. Emmett (Ed.), Catalysis, Catalytic Dehydrogenation, Vol. III, Reinhold, New York, 1955.

[25] O.K. Bogdanova, A.P. Shcheglova, A.A. Balandin, I.P. Belomestnykh, Petrol. Chem. USSR 1 (1962) 120.
[26] M. Berthelot, Ann. Chim. Phys. 16 (1869) 156.

[27] W.W. Kaeding, Catal. Rev. 8 (1973) 307.

[28] K.K. Kearby, US Patent 2426829 (1947) to Standard Oil Development Corporation.

[29] E.H. Lee, Catal. Rev. 8 (1973) 285.

[30] H.P. Lin, S. Cheng, C.Y. Mou, Chem. Mater. 10 (1998) 581.

[31] T-R. Lin, B-Z. Wan, H.P. Lin, C.Y. Mou, Proc. 12th Int. Zeolite Conf., Baltimore, July 1998.

[32] C.N. Wu, T.S. Tsai, C.N. Liao, K.J. Chao, Microporous Mater. 7 (1996) 173.

[33] X. Wang, T. Dou, Y. Xiao, Chem. Commun. (1998) 1035.

[34] N. Coustel, F. Di Renzo, F. Fajula, J. Chem. Soc., Chem. Commun. (1994) 967.

[35] Y.-C. Xie, Y-Q. Tang, Adv. Catal. 37 (1990) 1.

[36] S. Gunther, M. Marsi, A. Kolmakov, M. Kiskinova, M. Noeske, E. Taglauer, G. Mestl, U.A. Schubert, H. Knozinger, J. Phys. Chem. B 101 (1997) 10004.

[37] H.M. Ismail, M.I. Zaki, G.C. Bond, R. Shukri, Appl. Catal. 72 (1991) L1.

[38] R. López Cordero, F.J. Gil Llambias, A. López Agudo, Appl. Catal. 74 (1991) 125.

[39] R. Thomas, E.M. Van Oers, V.H.J. De Beer, J.A. Moulijn, J. Catal. 84 (1983) 275.

[40] J. Chen, D. He, S. Cao, Chem. J. Chin. Univ. 7 (1986) 1020.

[41] K. Matsumoto, A. Kobayashi, Y. Sasaki, Bull. Chem. Soc. Jpn. 48 (1975) 1009. 